\title{
KINERJA TUNGKU GASIFIKASI DOWNDRAFT CONTINUE BAHAN BAKAR SEKAM PADI
}

\author{
Subroto \\ Jurusan Teknik Mesin Universitas Muhammadiyah Surakarta \\ Jl. A. YaniTromol Pos I Pabelan, Kartosuro \\ Email:sub224@ums.ac.id
}

\begin{abstract}
ABSTRAK
Gasifikasi adalah mengambil gas metana yang terkandung pada bahan bakar padat sehingga jika digunakan pembakarannya akan lebih bersih. Tujuan penelitian ini adalah untuk mendapatkan desain tungku gasifikasi yang efisien dengan merancang bangun dan menguji kinerja tungku tersebut. Kinerja tungku gasifikasi diuji dengan cara melihat karakteristik pembakarannya. Parameter karakteristik pembakaran meliputi temperatur pembakaran, waktu awal penyalaan dan lama nyala efektif pembakaran. Penelitian dimulai dengan merancang bangun tungku gasifikasi tipe downdraft continue, dimana aliran udara gasifikasi mengalir searah dengan gas metana yang dihasilkan. Bahan bakar dimasukan ke tungku secara periodik terus menerus selama proses pembentukan gas metana berlangsung, setelah terjadi pembentukan gas langsung dinyalakan. Gas asap hasil pembakaran dipakai untuk mendidih kan air, kemudian dicatat data temperatur pembakaran, waktu penyalaan awal, lama nyala efektif, temperatur air, dan lama pendidihan. Penelitian menghasilkan temperatur pembakaran tertingggi rata-rata hampir sama dengan isi ulang bahan bakar maupun tanpa isi ulang. Waktu penyalaan awal lebih cepat dengan isi ulang bahan bakar dibandingkan tanpa isi ulang. Lama nyala efektif pembakaran lebih lama dengan isi ulang dibandingkan tanpa isi ulang dan kalor hasil pembakaran lebih besar dengan isi ulang dibandingkan tanpa isi ulang.
\end{abstract}

Kata kunci: Gasifikasi, kinerja tungku, downdraft continue, sekam padi

\begin{abstract}
Gasification is the process of taking methane gas contained in the solid fuel so that if it is used will have cleaner combustion. The purpose of this study is to obtain efficient gasification furnace design by designing up and test the performance of the furnace. Gasification furnace performance tested by looking at the characteristics of the combustion including temperature combustion, the initial time of ignition and effective flame combustion time. The experiment begins by designing a type of downdraft continue gasification furnace, where the gasification air stream flowing with produced methane gas. Fuel is fed into the furnace periodically and continuously during the process of the formation of methane gas, after the formation of the gas, it is ignited. Gas fumes of combustion is used to boil water right away, then the combustion temperature data, startup time, effective flame combustion time, water temperature, and duration of boiling are recorded. Research generates that the highest average combustion temperatures almost the same as the fuel refill
\end{abstract}


or without a refill. Effective flame combustion time is longer with refill than without refill and heat combustion products with refills greater than without a refill.

Keywords: Gasification, furnace performance, downdraft continue, rice husk

\section{PENDAHULUAN}

Kenaikan dan fluktualisasi harga minyak dunia yang kini berimbas di dalam negeri menyebabkan adanya keresahan dalam masyarakat kelas menengah ke bawah. Reforminer Institude merilis data bahwa cadangan minyak Indonesia akan segera habis dalam kurun waktu 12 tahun. Saat ini cadangan minyak Indonesia hanya 3,7 milyar barel dan angka ini hanya sebesar $0,3 \%$ dari cadangan minyak dunia. Akhirnya Indonesia hanya mampu memproduksi sekitar 830.000 barel minyak per hari. Sementara itu di sisi lain Indonesia membutuhkan sekitar 1,2 juta barel perharinya.Kebijakan yang saat ini dilakukan pemerintah yaitu mengimpor minyak. Minyak bumi sebagaimana yang kita ketahui bersama adalah salah satu bentuk sumber daya alam yang tidak bisa diperbarui (nonrenewable) yang berasal dari sumber energy fosil. Sehubungan dengan hal tersebut, jumlah permintaan dan kebutuhan akan minyak terus meningkat. Hal ini mengakibatkan ketidak stabilan harga minyak seperti saat ini. Ketidakstabilan harga minyak dunia ini berimbas pada fluktuasi harga bahan bakar minyak Indonesia, yang kini mulai menghapus subsidi minyak dengan maksud untuk mengurangi beban negara. Kini setidaknya pemerintah cukup berhasil mengurangi penggunaan BBM dengan program konversi gas khususnya pada kebutuhan dapur. Namun demikian, kelancaran distribusi, fluktuasi harga serta ketersediaan gas masih dirasa sering menjadi masalah dalam masyarakat.

Salah satu cara dalam menyelesaikan masalah tersebut adalah dengan mencari sumber energi alternatif yang bisa diperbarui (renewable) dan tersedia dalam jumlah yang culup besar. Sumber energy tersebut seperti energi matahari, angin, energi potensial air hingga limbah. Energi alternative adalah salah satu bentuk teknologi yang menghasilkan bahan bakar selain minyak bumi, dapat digunakan secara berulang, tersedia dalam jumlah yang cukup besar, tidak merusak alam, murah dan aman. Penelitian dan penemuanpun kini gencar dilakukan oleh para ilmuan serta akademisi di tiap negara di dunia tak terkecuali di Indonesia. Pengembangan dan penyempurnaan menjadi hal yang terus digalakkan guna mencapai sebuah efisiensi penggunaan dan kenyamanan penggunaan bahan energi alternatif tersebut. Hal itu disebabkan agar masyarakat dapat tertarik dengan penggunaan teknologi energi alternatif yang murah, mudah serta aman digunakan.

Kelebihan gasifikasi tipe downdraft dapat disi bahan bakar secara kontinu terus menerus selama proses pembentukan gas berlangsung tanpa menghentikan penyalaan pembakaran. Sudah banyak tungku jenis dikembangkan tetapi masih terdapat kekurangan antara lain : selama proses pembentukan gas proses termokimia masih kurang lancar, penyalaan awal diperlukan waktu yang cukup lama, temperatur pembakaran maih kurang stabil dan lainlain. Percobaan telah banyak dilakukan oleh peneliti dan para praktisi menyimpulkan banyak faktor banyak yang terjadi selama proses gasifikasi .

Alexis [1] menyimpulkan dari hasil penelitiannya bahwa sudut throut berpengaruh terahadap laju reaksi, semakin besar sudut throat maka suhu dan laju reaksi semakin rendah. Dasar analisis tersebut dipakai Dziyad et al [2] untuk melanjutkan penelitian, dan menyimpulkan bahwa desain throat pada pangkal reaktor gasifikasi sangat berpengaruh terhadap kelancaran reaksi termokimia yang akan berlangsung pada proses gasifikasi. Maka parameter yang dianggap penting sebagai dasar pengembangan desain tungku gasifikasi jenis downdraf adalah diameter tungku, tinggi tungku dan sudut throat. 


\section{TINJAUAN PUSTAKA}

Wusana, dkk [3] merancang dan menguji kinerja Reaktor Gasifikasi Sekam Padi Skala Kecil. Menjelaskan bahwa pembuatan tungku gasifikasi dengan skala kecil dengan dimensi diameter reaktor $13,97 \mathrm{~cm}$ dan tinggi reaktor $60 \mathrm{~cm}$ sudah mampu dioperasikan dengan cukup mudah dan memiliki nyala api yang cukup stabil. Dengan hasil lidah api mulai terlihat pada ujung burner di 6-7 menit setelah start up terhitung pada awal penyalaan tungku.

Isaac, dkk [4] menjelaskan tentang rancangan aliran udara dalam perancangan tungku gasifikasi sekam padi skala kecil untuk memasak. Bahwa dalam merancang tungku dengan tipe penggunaan yang berkelanjutan, diharuskan untuk memperhitungkan tahap pyrolisis agar dapat berjalan lancar. Yaitu dengan memberikan pipa pengarah agar suplai oksigen cukup dalam proses ini.

Dziyad dan Wulandani [2] Menganalisis dengan Computational Fluid Dynamics untuk Perancangan Reaktor Gasifikasi Sekam Padi Tipe Downdraft menerangkan bahwa rancangan outlet reaktor yang terdiri dari sudut throat mempengaruhi nilai kalor yang dihasilkan oleh tungku. Desain outlet sudut throat yang mampu menghasilkan nilai kalor paling tinggi adalah desain sudut throat $90^{\circ}$ diukur dari garis yang tegak lurus dengan reaktor.

Bambang, dkk [5] Mengkaji Dimensi Tenggorokan Ruang Reduksi Gasifier Tipe Downdraft Untuk Gasifikasi Limbah Tongkol Jagung. Menyimpulkan bahwa desain throat atau tenggorokan tungku dan tinggi ruang reduksi berpengaruh nyata terhadap nyala efektif tungku dan produksi gas metan. Waktu nyala efektif yang besar ditentukan oleh suhu reduksi yang tinggi dan stabil. Suhu diatas $350^{\circ}$ dan tinggi ruang reduksi $10 \mathrm{~cm}$ mampu memberikan kinerja gasifikasi optimal.

\section{Gasifikasi Biomassa}

Gasifikasi adalah proses yang berbeda dengan proses pembakaran maupun proses pembentukan biogas. Perbedaan gasifikasi dengan pembakaran terletak pada jumlah oksigen yang digunakan dalam prosesnya, serta produk yang dihasilkan. Proses pembakaran menggunakan oksigen yang melebihi kebutuhan stokiometrik, selain itu produk yang dihasilkan berupa energi panas dan gas yang tidak terbakar.

Sementara itu, proses gasifikasi sangat bergantung pada reaksi kimia yang terjadi pada temperatur di atas $600{ }^{\circ} \mathrm{C}$. Hal inilah yang membedakannya dengan proses biologis seperti proses anaerobik yang menghasilkan biogas. Gasifikasi adalah proses pengubahan materi yang mengandung karbon seperti batubara, minyak bumi, maupun biomassa ke dalam bentuk karbon monoksida $(\mathrm{CO})$ dan hidrogen $\left(\mathrm{H}_{2}\right)$ dengan mereaksikan bahan baku yang digunakan pada temperatur tinggi dengan jumlah oksigen yang diatur. Tujuan dari proses ini adalah untuk mengubah unsur-unsur pokok dari bahan bakar yang digunakan ke dalam bentuk gas yang lebih mudah dibakar, sehingga hanya menyisakan abu dan sisa-sisa material yang tidak terbakar (inert).

Proses gasifikasi biomassa dilakukan dengan cara melakukan pembakaran secara tidak sempurna di dalam sebuah ruangan yang mampu menahan temperatur tinggi yang disebut reaktor gasifikasi. Agar pembakaran tidak sempurna dapat terjadi, maka udara dengan jumlah yang lebih sedikit dari kebutuhan stokiometrik pembakaran dialirkan ke dalam reaktor untuk mensuplai kebutuhan oksigen menggunakan kipas atau blower. Proses pembakaran yang terjadi menyebabkan reaksi termo-kimia yang menghasilkan $\mathrm{CO}, \mathrm{H}_{2}$, dan gas metan $\left(\mathrm{CH}_{4}\right)$. Selain itu, dalam proses ini juga dihasilkan uap air $\left(\mathrm{H}_{2} \mathrm{O}\right)$ dan karbon dioksida $\left(\mathrm{CO}_{2}\right)$ yang tidak terbakar. 


\section{Tahapan gasifikasi}

1. Pyrolisis yang terjadi ketika biomassa mulai mengalami kenaikan temperatur. Pada tahap ini volatil yang terkandung pada biomassa terlepas dan menghasilkan arang (char).

2. Proses pembakaran (combustion) pada tahapan ini volatil dan sebagian arang yang memiliki kandungan karbon (C) bereaksi dengan oksigen membentuk $\mathrm{CO}$ dan $\mathrm{CO}_{2}$ serta menghasilkan panas yang digunakan pada tahap selanjutnya yaitu tahap gasifikasi.

- Reaksi pembakaran $\mathrm{C}+1 / 2 \mathrm{O}_{2}=\mathrm{CO}$

- $\quad$ Reaksi Boudouard $\mathrm{C}+\mathrm{CO}_{2}=2 \mathrm{CO}$

3. Gasifikasi tahapan ini terjadi ketika arang bereaksi dengan $\mathrm{CO}_{2}$ dan uap air yang menghasilkan gas $\mathrm{CO}$ dan $\mathrm{H}_{2}$ yang merupakan produk yang diinginkan dari keseluruhan proses gasifikasi.

- Reaksi water gas $\mathrm{C}+\mathrm{H}_{2} \mathrm{O}=\mathrm{CO}+\mathrm{H}_{2}$

4. Water shift reaction. Melalui tahapan ini, reaksi termo-kimia yang terjadi di dalam reaktor gasifikasi mencapai keseimbangan. Sebagian CO yang terbentuk dalam reaktor bereaksi dengan uap air dan membentuk $\mathrm{CO}_{2}$ dan $\mathrm{H}_{2}$.

- Reaksi metana $\mathrm{C}+2 \mathrm{H}_{2}=\mathrm{CH}_{4}$

\section{Tipe-Tipe Reaktor Gasifikasi Biomassa}

\section{Reaktor Gasifikasi Tipe Updraft}

Pada reaktor gasifikasi tipe ini, zona pembakaran (sumber panas) terletak di bawah bahan bakar dan bergerak ke atas seperti tampak dalam Gambar Dalam gambar ini tampak bahwa gas panas yang dihasilkan mengalir ke atas melewati bahan bakar yang belum terbakar sementara bahan bakar akan terus jatuh ke bawah. Melalui pengujian menggunakan sekam padi, reaktor gasifikasi ini dapat bekerja dengan baik. Kekurangan dari reaktor.

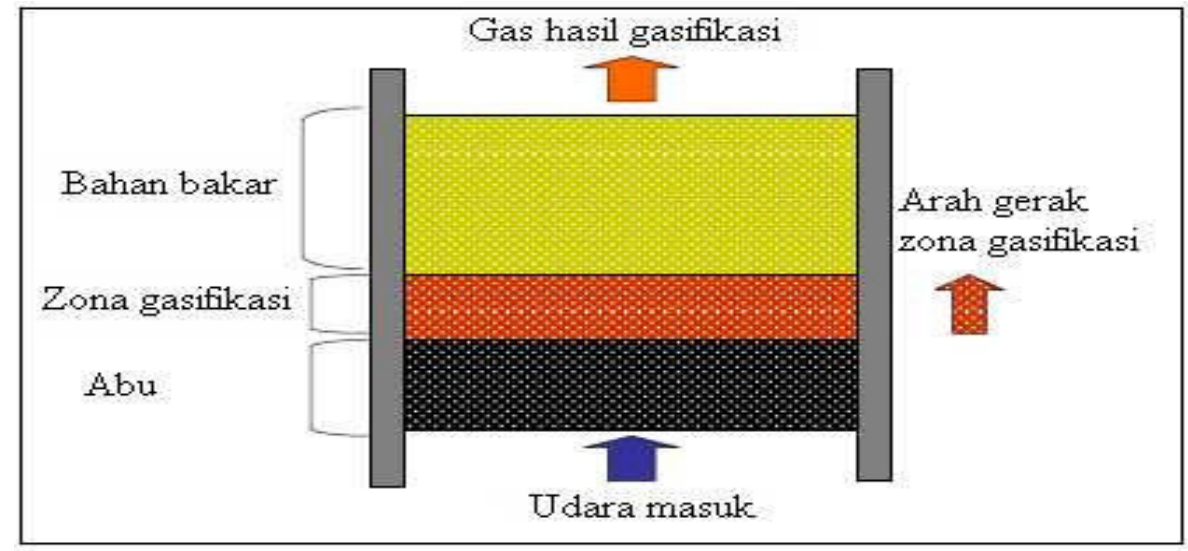

Gambar 1. Skema Reakor Gasifikasi Tipe Updraft

\section{Reaktor Gasifikasi Tipe Downdraft}

Pada tipe ini sumber panas terletak di bawah bahan bakar seperti tampak dalam gambar di bawah. Aliran udara bergerak ke zona gasifikasi di bagian bawah yang menyebabkan asap pyroslisis yang dihasilkan melewati zona gasifikasi yang panas. Hal ini membuat tar yang terkandung dalam asap terbakar, sehingga gas yang dihasilkan oleh reactor ini lebih bersih. Keuntungan reaktor tipe ini adalah reaktor ini dapat digunakan untuk operasi gasifikasi yang berkesinambungan dengan menambahkan bahan bakar melalui bagian atas reaktor. Namun untuk operasi yang berkesinambungan dibutuhkan sistem pengeluaran abu yang baik, agar bahan bakar bisa terus ditambahkan. 


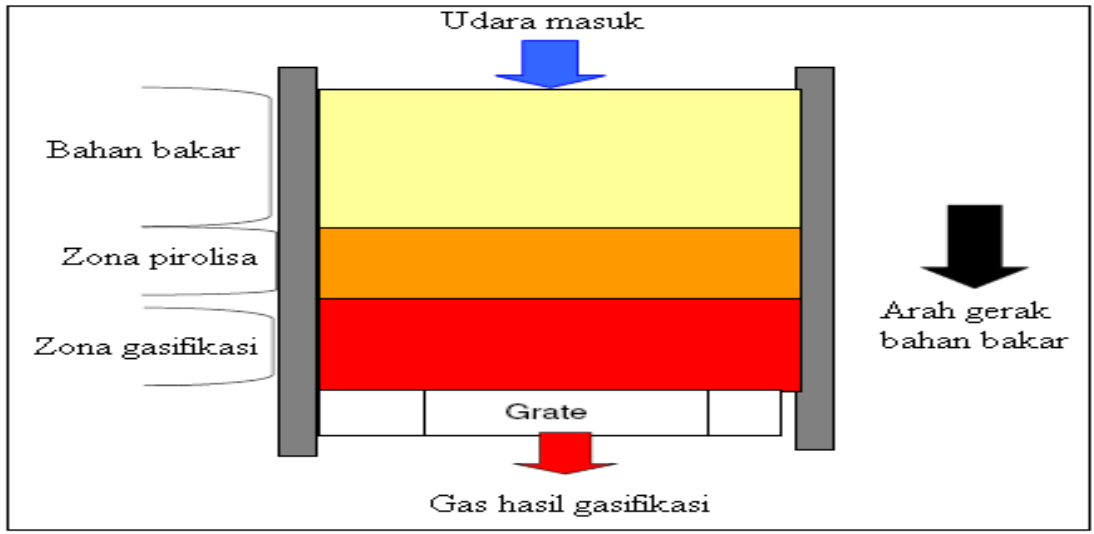

Gambar 2. Skema Reakor Gasifikasi Tipe Downdraft

\section{Reaktor Gasifikasi Tipe Inverted Downdraft}

Prinsip kerja reaktor gasifikasi tipe ini sama dengan prinsip kerja reactor gasifikasi downdraft gasifiers. Dalam gambar tampak bahwa perbedaan antara reaktor gasifikasi downdraft gasifiers dengan reactor gasifikasi inverted downdraft gasifiers terletak pada arah aliran udara dan zona pembakaran yang dibalik. Sehingga bahan bakar berada pada bagian bawah reaktor dengan zona pembakaran di atasnya. Aliran udara dari bagian bawah ke bagian atas reaktor.

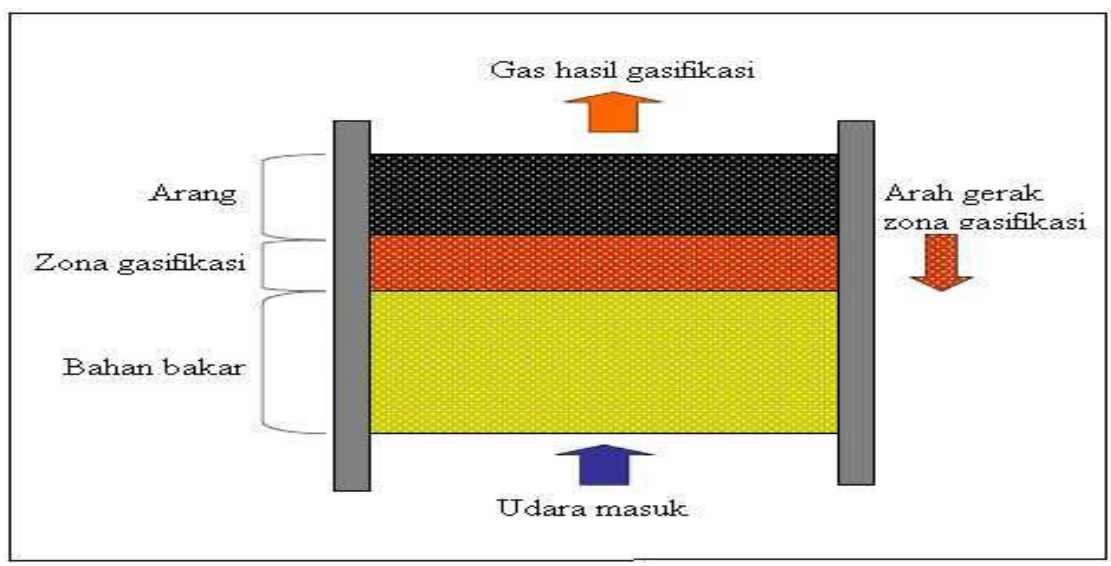

Gambar 3. Skema Reakor Gasifikasi Tipe Inverted Downdraft

\section{Reaktor Gasifikasi Tipe Crossdraft}

Pada reaktor ini, aliran udara mengalir tegak lurus dengan arah gerak zona pembakaran. Reaktor tipe ini memungkinkan operasi yang berkesinambungan apabila memiliki sistem pengeluaran abu yang baik.

\section{Diameter reaktor}

$\boldsymbol{D}=\left(\frac{1,27 F C R}{S G R}\right)^{0,5}$

Dimana:

$\mathrm{D}: \quad$ diameter reactor $(\mathrm{m})$

FCR: fuel consumtion rate atau konsumsi bahan bahar rata-rata $(\mathrm{kg} / \mathrm{hr})$ 
SGR: specific gasification rate of rice husk atau rata-rata gasifikasi sekam padi (110-210 $\mathrm{kg} / \mathrm{m}^{2} . \mathrm{hr}$ )

1. Tinggi Reaktor Tungku

$\boldsymbol{H}=\frac{S G R \times T}{\rho_{r h}}$

Dimana:

$\mathrm{H}$ : Tinggi Reactor (m)

$\mathrm{T}$ : Waktu konsumsi bahan bakar (hr)

$\rho^{\text {rh }}:$ density sekam padi $\left(\mathrm{kg} / \mathrm{m}^{3}\right)$

\section{METODE PENELITIAN}

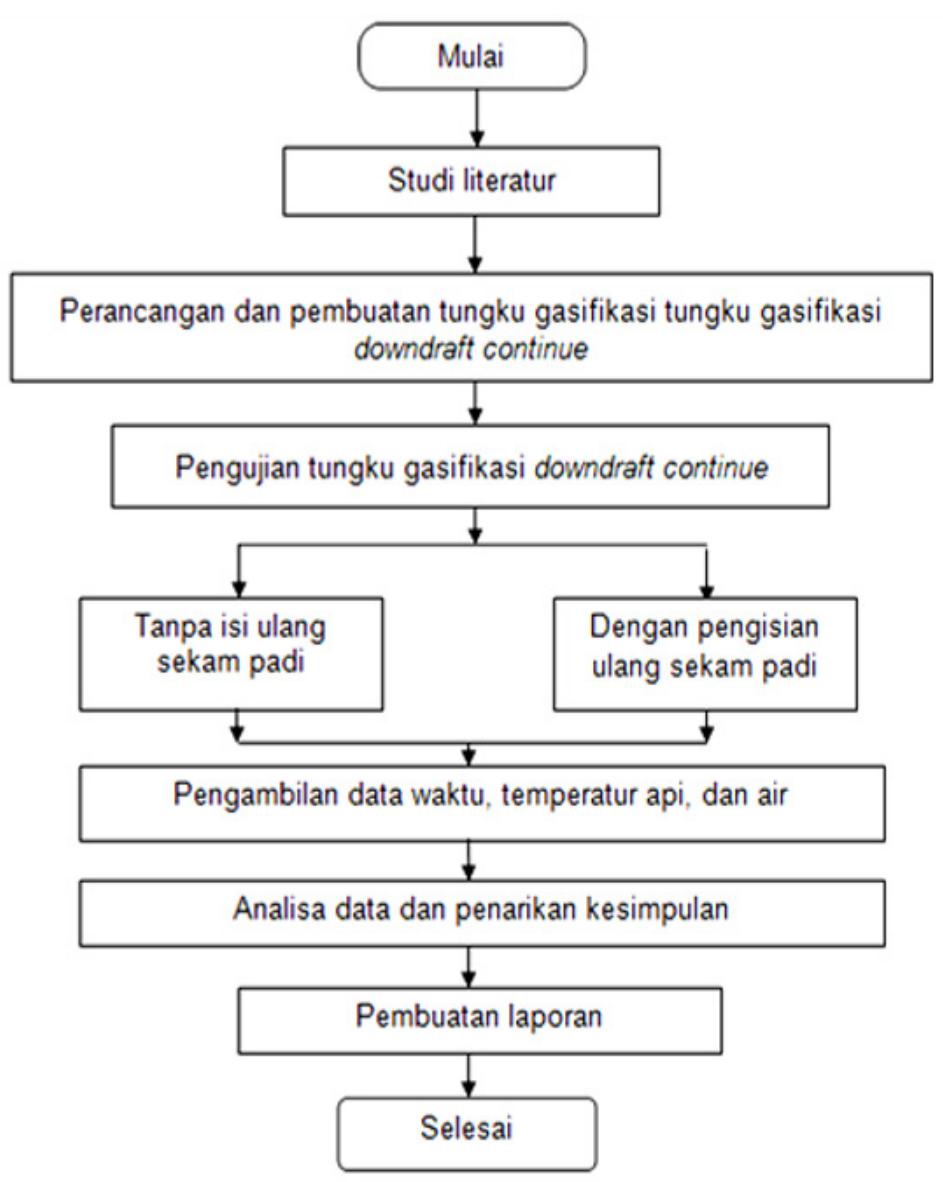

Gambar 4. Diagram Alir Penelitian 


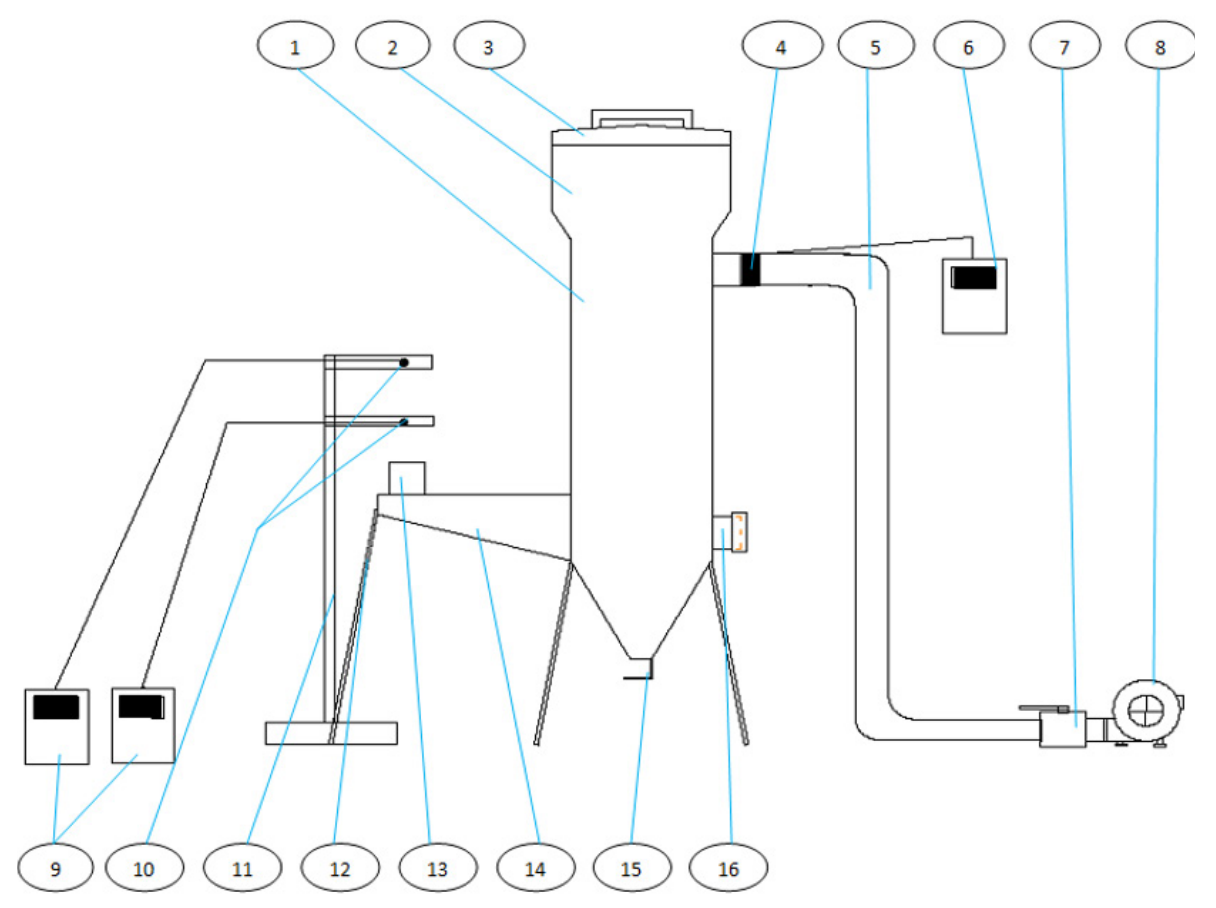

Gambar 5. Instalasi Pengujian

Keterangan:

1. Tungku gasifikasi spesifikasi :

Diameter $=170 \mathrm{~mm}$

Tinggi $=650 \mathrm{~mm}$

Sudut throut $=60^{\circ}$

2. Tempat bahan bakar

3. Penutup tungku

4. Anemometer

5. Saluran udara pembakaran

6. Anemometer reader

7. Saluran udara masuk tungku

8. Fan

9. Thermocouple reader

10. Thermocouple

11. Penyangga thermocouple

12. Dudukan tungku

13. Saluran gas keluar

14. Pipa saluran penghubung

15. Saluran sisa bahan bakar

16. Saluran penyalaan awal 


\section{HASIL DAN PEMBAHASAN}

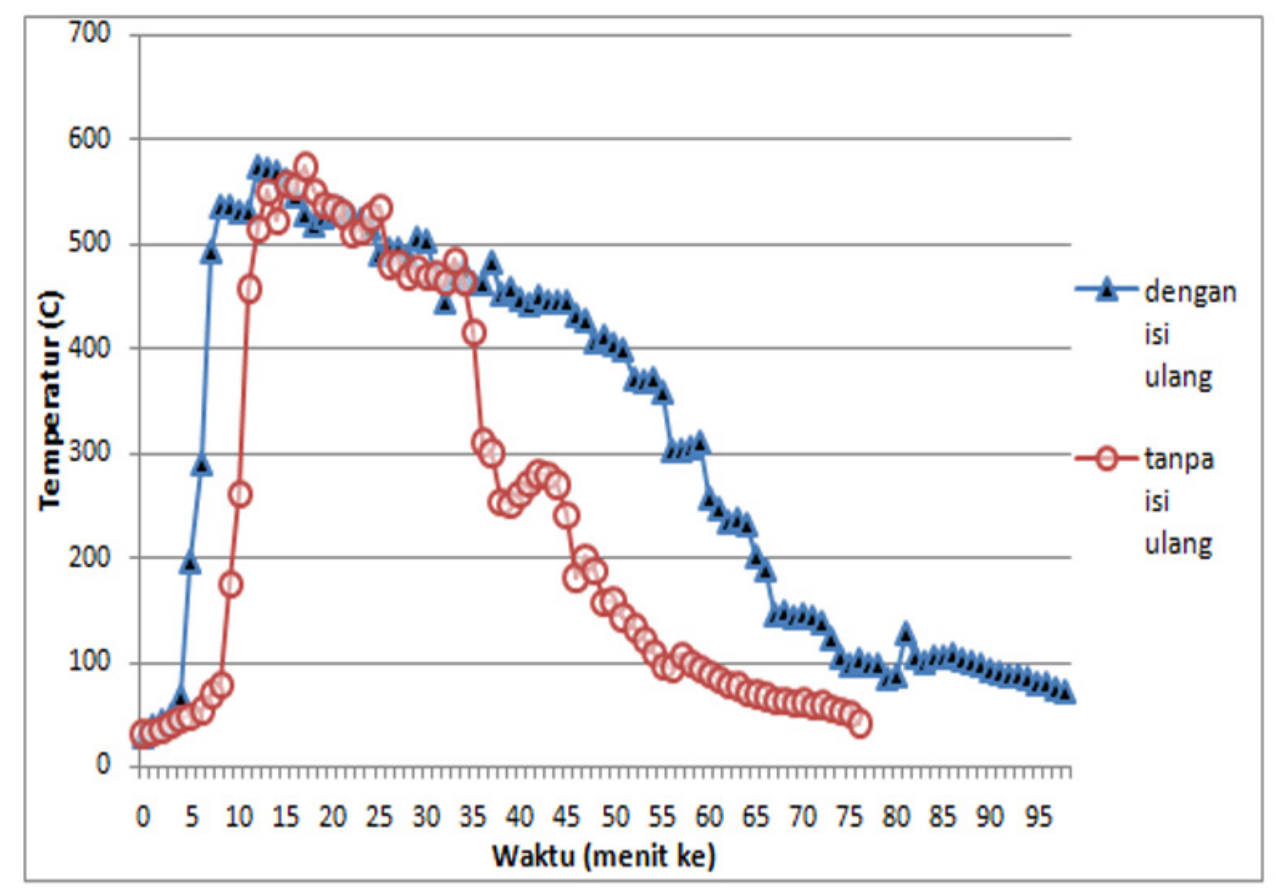

Gambar 6. Perbandingan Karakteristik Temperatur Pembakaran

Dari gambar 6 grafik perbandingan karakteristik pembakaran gasifikasi tunggku jenis downdraf kontinu dapat dijelaskan bahwa hasil karakteristik pembakaran mempunyai karakter yang sama atau sangat signifikan antara dengan bahan bakar isi ulang atau tanpa isi ulang. Setelah terjadi pembentukan gas metana dan terjadi penyalaan awal terjadi lonjakan temperatur dengan cepat kemudian gas metana terus terbentuk sampai temperatur akan turun dengan drastis, hal ini terjadi karena gas metana yang terbentuk sudah habis.

Temperatur pembakaran yang terukur hampir sama yang isi ulang $573{ }^{\circ} \mathrm{C}$ sedangkan yang tanpa isi ulang $572^{\circ} \mathrm{C}$, hal ini karena perlakuan penelitian sama dengan jenis bahan bakar yang sama pula. Sedangkan waktu penyalaan lebih cepat yang dengan yang isi ulang selama 6 menit dan 10 menit yang tanpa isi ulang, fenomena ini terjadi karena yang isi ulang kondisi dinding tungku sudah diatas suhu kamar sehingga siap untuk pembakaran. Dinding tungku temperatur sudah naik, sehingga akan mempercepat proses gasifikasi. 


\section{Gambar 7. Perbandingan Lama Nyala Efektif Pembakaran}

Dari gambar 7 dapat dijelaskan kecepatan udara dibuat konstan dengan jenis bahan bakar yang sama dan kapasitas bahan bakar awal yang sama, menghasilkan nyala efektif yang sama. Dengan isi ulang bahan bakar menghasilkan nyala efektif api tungku hingga 62 menit sedangkan penggunaan tungku tanpa diisi ulang mampu menyala selama 36 menit. Hal ini karena kapasitas bahan bakar yang dipakai lebih banyak akan menghasilkan nyala api yang lebih lama.

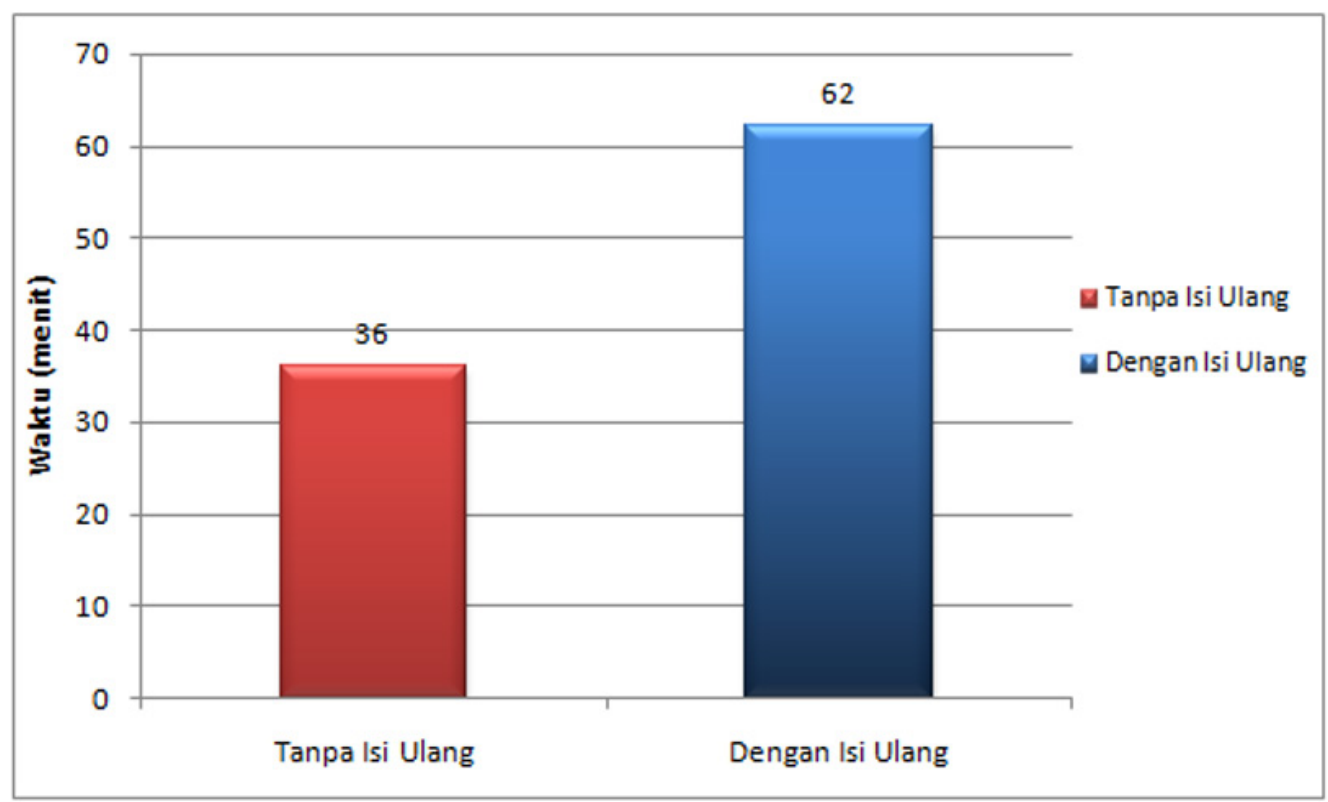

Gambar 8. Perbandingan Temperatur Air Boiling Test

Pada gambar 8 di atas dapat dilihat grafik fenomena suhu pendidihan dari hasil boiling test hasil pembakaran dipakai untuk mendidihkan air. Waktu yang diperlukan untuk pendidihan air baik yang isi ulang maupun yang tanpa isi ulang memililki waktu yang sama yaitu 15 menit. Temperatur tertinggi air juga relatif sama, yang berbeda adalah kapasitar air yang didihkan menjadi uap. Dengan tungku yang diisi ulang bahan bakar mampu mendidihkan air sebanyak 1,480 liter, sedangkan yang tanpa diisi ulang mampu mendidihkan air sebanyak 0,740 liter. Hal ini disebabkan karena dengan bahan bakar isi ulang nyala efektifnya lebih lama.

Tabel 1 .Kalor Pendidihan Air

\begin{tabular}{|c|c|c|c|c|c|}
\hline & $M$ air $(\mathrm{Kg})$ & $\mathrm{Cp}\left(\mathrm{Kj} / \mathrm{Kg}^{\circ} \mathrm{C}\right)$ & $\Delta \mathrm{T}\left({ }^{\circ} \mathrm{C}\right)$ & Qs $(\mathbf{K j})$ & M uap (kg) \\
\hline Dengan isi ulang & 3 & 4.1925 & 74 & 930.73 & 1.48 \\
\hline Tanpa Isi ulang & 3 & 4.1925 & 74 & 930.73 & 0.73 \\
\hline & $h_{\mathrm{fg}}(\mathrm{Kj} / \mathrm{Kg})$ & $\mathbf{Q L}(\mathbf{K} \mathbf{j})$ & Qs (Kj) & QL (Kj) & $Q$ total $(\mathbf{K} \mathbf{j})$ \\
\hline Dengan isi ulang & 2323.3 & 3438.48 & 930.73 & 3438.48 & 4369.21 \\
\hline Tanpa Isi ulang & 2323.3 & 1696.00 & 930.73 & 1696.00 & 2626.74 \\
\hline
\end{tabular}


Dari tabel 1. proses gasifikasi sekam padi nilai kalor yang dihasilkan dengan isi ulang menghasilkan kalor sebesar4326, $216 \mathrm{~kJ}$ sedangkan tanpa isi ulang mampu menghasilkan kalor sebesar 2626,744 kJ. Dengan isi ulang menghasilkan kalor yang lebih banyak, hal ini karena dengan isi ulang menggunakan bahan bakar yang lebih banyak.

\section{KESIMPULAN}

Setelah melakukan pengujian, analisa dan pembahasan pada kinerja tungku gasifikasi downdraft continue dapat kesimpulan sebagai berikut:

1. Temperatur pembakaran rata-rata tertinggi pembakaran hampir sama dengan isi ulang maupung tanpa isi

2. Waktu penyalaan lebih cepat dengan isi ulang dengan waktu 6 menit dibandingkan tanpa isi ulang dengan waktu 10 menit

3. Lama nyala efektif dengan isi ulang waktu 62 menit lebih lama dibandingkan tanpa isi ulang waktu 36 menit.

4. Nilai kalor hasil gasifikasi untuk isi ulang 4369,21 kJ lebih besar dibandingkan tanpa isi ulang $2626,74 \mathrm{~kJ}$.

\section{DAFTAR PUSTAKA}

[1] Belonio T Alexis., 2011, Rice Husk Gas Stove dan Household-Size Continuous-Flow Rice Husk Gas Stove, Filipina.

[2] Dziyad Dzulfansyah, Leopold Oscar Nelwan, Dyah Wulandani, 2014, Analisis Computational Fluid Dynamics untuk Perancangan Reaktor Gasifikasi Sekam Padi Tipe Downdraft, Departemen Teknik Mesin dan Biosistem, Institut Pertanian Bogor.

[3] Wusana Agung W, Sunu H Pranolo, Gede Noorochadi, Lusia Ratna M, 2010, Perancangan dan Uji-Kinerja Reaktor Gasifikasi Sekam Padi Skala Kecil, Fakultas Teknik. Universitas Sebelas Maret Surakarta.

[4] Isaac Lockman, Marc Par'e, Jordan Edwards, 2010, Design od a Rice Husk Gasification Cook Stove for Rural Nicaragua, Mechanical Engineering, Georgia Institude of Technology.

[5] Bambang Purwantana, dkk, 2011, Kajian Dimensi Tenggorokan Ruang Reduksi Gasifier Tipe Downdraft Untuk Gasifikasi Limbah Tongkol Jagung, Jurusan Teknik Pertanian Fakultas Teknologi Pertanian Universitas Gadjah Mada 